Article

\title{
Thermal Transmittance Measurements of the Historical Masonries: Some Case Studies
}

\author{
Marianna Rotilio ${ }^{1}$, Federica Cucchiella ${ }^{2, *(\mathbb{D})}$, Pierluigi De Berardinis ${ }^{1}$ and Vincenzo Stornelli ${ }^{2}$ (I) \\ 1 Department of Civil, Construction-Architectural and Environmental Engineering, University of L'Aquila, \\ Via G. Gronchi n. 18, 67100 L'Aquila, Italy; mariannarotilio@hotmail.com (M.R.); \\ pierluigi.deberardinis@univaq.it (P.D.B.) \\ 2 Department of Industrial and Information Engineering and Economics, University of L'Aquila, \\ Via G. Gronchi n. 18, 67100 L'Aquila, Italy; vincenzo.stornelli@univaq.it \\ * Correspondence: federica.cucchiella@univaq.it; Tel.: +39-0862-434464
}

Received: 5 August 2018; Accepted: 24 October 2018; Published: 1 November 2018

check for updates

\begin{abstract}
The background shows that intervention on historical walls highlights the difficulty of identifying design solutions that are effective and compatible due to the lack of specific data on the thermal characteristics of the specific contexts investigated. This determines the choice of design solutions that are frequently inadequate and unsustainable from an environmental and economic point of view. Starting from acquired data a methodology has been developed that is based on in situ experimental investigations able to return the most probable value of transmittance of the historical walls. The values measured on the samples analysed do not reflect the literature data. For some of the samples analysed, the measured transmittance is lower than the one recorded in literature of about $10-15 \%$. For the remaining ones, there are no reference values. The importance of an in-depth knowledge of the real behaviour of an existing historical envelope of a building is therefore fundamental, given that any evaluation mistake can have serious consequences from both an economic and environmental point of view. Underestimating the transmittance of a wall implies a waste in the use of available resources but also the disposal of greater quantities of building materials in relation to the end of life. The developed methodology can be easily replicated in other contexts and extended to all building elements that make up the historical envelope. The study will be continued by analysing further samples in order to create a reference knowledge database accessible to researchers, professionals and organizations.
\end{abstract}

Keywords: historical wall; energy efficiency; transmittance; thermal flux survey; test project

\section{Introduction}

The willingness to operate on existing buildings, in particular on historic ones, represents the opportunity to support the building recovery with the introduction of innovative technologies that contribute to ensuring the environmental comfort of contemporary users. In these contexts, however, it is important to start by carrying out a preliminary analysis of the state of the building envelope through an accurate survey of the wall structures, the stratigraphy, the materials used, the degradation conditions, ... for the development of any project aimed at increasing the energy efficiency of the building envelope [1]. The intervention on historical walls in fact highlights the difficulty of identifying design solutions that are effective and compatible due to the lack of specific data on the thermal characteristics of the specific contexts investigated. In particular, the lack of input data (for example, transmittance and thermal resistance) often determines the need to resort to literature data, often distant from the real ones. This determines the choice of design solutions that are frequently inadequate, 
oversized and therefore incompatible and unsustainable from an environmental and economic point of view.

Both in large or small cities, the preservation of historical structures can be very important for the economic development. The architectural fabric of the city is woven into its neighbourhoods providing identity, sense of place and marketing of place [2].

For this reason, a preliminary energy diagnosis of historic buildings through in situ measurements becomes essential.

In fact the historical building fabric is the result of local knowledge and the use of materials found in situ [1,3]. Therefore, information between different sites characterized by different construction realities cannot be generalized. In light of this consideration, specific investigations on the energy diagnosis of the existing historical buildings are necessary to know the basic "initial" data for the development of any project on the efficiency of the building envelope [4]. The intervention on historical walls, in fact, highlights the difficulty of identifying design solutions that are effective and compatible due to the lack of specific data on their thermal characteristics. In particular, reference is made to thermal transmittance. In fact, the energy requirement of the building is proportional to the thermal transmittance of the opaque and transparent elements constituting the building envelope, which is the indicator of the energy efficiency (this indicator has been analysed by several authors with similar results [5-8]) of the building and of the relative running cost [9]. As known, the transmittance is equal to the inverse of the thermal resistance, a value that is strictly dependent on the thermal conductivity of each material that constitutes the stratigraphy of a wall. However, when no information is available on the characteristics of the materials composing the wall, reference and literature values can be used. Specifically Corrado, V. et al. [10] have investigated the transmittance value estimated through a research project and [11-13] can be used as legislative reference values.

Since the difference between the project and the actual data is linked to numerous factors, often not directly observable, we often resort to the experimental approach for the direct evaluation of the thermal resistance of the elements making up the building envelope $[8,14]$. A similar approach can also be used in relation to historical walls. In fact, when the intervention concerns such a context, often there is no information available on the stratigraphy of the wall, on the type and characteristics of the materials and cannot be acquired by means of destructive methods. Furthermore, the use of literature data often leads to incorrect evaluations due to the distance between them and reality. At international level it is clear that a certain level of knowledge of the energetic behaviour of historical buildings has not yet been acquired, nor are there any agreements on performance improvement strategies that take into account the values of cultural, historical, architectural, technical and construction heritage $[15,16]$. Therefore, the development of a correct energy analysis can help to identify the best rehabilitation solutions that are compatible, respectful of the values to be conserved and that can guarantee user comfort and energy efficiency $[17,18]$.

In this perspective, effective and accurate electronic equipment have to be designed for specific in situ tests both for short and long period analysis [19]. It is necessary to provide dedicated equipment and sensors systems for the management of the work in terms of diagnosis and control [20]. For infrastructures and civil structures, long-term monitoring is necessary for diagnosis. A sensory based monitoring system communicating with custom datalogger and node is of valuable perspective. The datalogger must be able to acquire the data coming from the nodes through wired communication and to synchronize acquisitions [21]. Furthermore, the datalogger must have internal memory for collecting data for post-processing. The nodes, apart from sensors, must incorporate a general-purpose microcontroller and an external memory for storage measures [22].

Starting from acquired data a methodology has been developed that is based on in situ experimental investigations able to return the most probable value of transmittance of the historical walls. This in one of the key parameters for the calculation of the energy efficiency of the building [23].

The main objective of the research carried out was to identify the transmittance of the historical wall selected in the specific context under investigation. In order to achieve this goal, the progressive 
average method of the UNI ISO 9869: 1994 standard was used. Jihyun, O. et al. and Seo-Hoon Kim et al. stated that standard " ... is an exceedingly accurate diagnostic method when the data measured via the in situ measurement of thermal transmittance is in a quasi-steady state" [1,24].

The literature shows the existence of studies in this direction, the results of which relate to specific contexts, given the already mentioned specificity of materials and local construction techniques. For example, Reference [16] realizes experimental measurements on the thermal transmittance of several ancient walls made of stone, bricks and mixed materials. References $[25,26]$ compares among standard, calculated and measured data in the case of historical brick masonries and in the case of historical stone masonries. Finally, the results were compared with the national standard, like in a previous study [27]. In the so-called "Limestone area of L'Aquila" [28], although there are numerous studies related to the historical walls [29], minor centres [30] and the local building techniques [31], there are no structured studies aimed at understanding the thermal attraction of the historical walls.

For this reason, in this paper we propose an experimental methodology aimed at identifying the most probable value of thermal transmittance of the historical walls in the above mentioned area, considering that according to an Italian research [32] even when using the same material, the transmitted transmittance values may vary, because different origins correspond to different values of $\lambda$.

This experimental methodology has been applied and verified in some case studies, specifically, this paper aims to illustrate the results achieved in a small village located in Italy, in the Abruzzo Region, in the Province of L'Aquila, which were then compared to literature data. The case studies have been identified as a function of construction solutions, with the aim of investigating the most recurring ones. The choice of the sample walls has been carried out following a series of in-depth analyses to verify that suitable monitoring conditions have occurred. Therefore, it has not always been possible to identify the most significant samples. In conclusion, this paper aims to illustrate the results obtained by highlighting the similarities and differences between the various case studies, also in order to increase the knowledge on historical buildings.

\section{Materials and Methods}

The starting point of the methodology developed is the knowledge acquired following the experimental investigations carried out during the development of a previous research $[23,28]$ but it has been expanded and deepened in several case studies verified within an entire historic village. This small town, due to its construction characteristics and the values it preserves on a historical and architectural level, can be considered a sufficiently representative village within the wider territorial context in which it is inserted. Before implementing the experimentation, initial analyses have been necessary to identify and classify the main types of vertical opaque closures in the centre. Therefore, a preliminary historical analysis was carried out, such as to understand the main stages of growth of the village and its fabric, in order to identify its dating. Afterwards, given the extension of the village, a subdivision in zones was made for the only purpose of facilitating the initial survey operation of the wall types.

Since the reliability of the tests is linked to the occurrence of certain conditions, the thermal performance of masonries has been measured using the heat flow-meter measurement (HFM), a Non-Destructive Testing (NDT), that permits to determine the thermal transmittance properties of the opaque envelope directly in situ. The procedure is regulated by UNI ISO 9869: 1994. According to this rule the measurements can be considered reliable under certain conditions summarized below:

i. they must be performed in accessible areas with confined spaces; on walls not exposed to direct sunlight;

ii. in environments where the internal temperature is constant, close to 20 degrees and with an internal-external difference of at least 10-15 degrees;

iii. in the absence of inversion of the thermal flux, that is, with external temperatures higher than 5-10 degrees; 
iv. finally, electricity is necessary to allow the use of the technical equipment.

In addition, the measurement must last for several days and must be performed on a portion of the wall the most uniform as possible, that is, equidistant from other construction elements (doors, windows, corner nodes, ...) and representative of the wall as a whole [33].

In light of the above listed constraints, it was necessary to develop the so-called "Test Project," consisting of three distinct phases:

- the definition of the elements under investigation,

- the implementation of the survey itself,

- data meaning and interpretation,

- calculation of the transmittance value.

The first of the three phases was developed through the identification, analysis and mapping of the wall types present in the historic village. The buildings in which the masonry has remained uncovered show the various stratifications, collapses and reconstructions that have occurred over time. Normally, the buildings covered with plaster conceal the wall structure making impossible to recognize the different stratifications and connections with the new interventions, leaving only the calcareous stone worked in correspondence with the door and window and/or corners. But often, if there are any collapses, the exact stratigraphy can be reconstructed.

The second phase is aimed at defining the choice parameters in the selection of the wall samples studied. This step is essential to allow compliance with the measurement conditions previously listed in the UNI ISO 9869 standard.

Therefore, once the wall types have been identified, a second mapping of the historical village has been carried out indicating collapses, demolitions, areas not accessible due to the presence of rubble and the presence or absence of window frames. This operation led to the elimination of all buildings not suitable for the tests. Through the synthesis of these analyses the buildings and the relative "sample walls" were chosen. Subsequently, a metric-structural survey was elaborated and both the space distribution and functional aspects and the technological elements constituting the building envelope were analysed. The in-depth study was also performed in order to identify the most undisturbed and uniform wall samples, without thermal bridges. The presence of the latter has been verified by means of thermographic analysis in accordance with standard (IS0 6781:1983).

At that point, it was possible to start with the measurements. The instrumentation used consisted of a flat-plat thermal flux meter located inside the building, a wireless temperature probe, placed outside and two probes measuring the surface temperatures of the two sides of the wall also positioned near it (Figure 1). To guarantee perfect adherence between the plate probe and the wall, the thermo-conductive paste was used, while the plasticine clay was used for the temperature probes.

Due to the difficulty of keeping the stationary conditions due to the variability of the forcing agents acting on the building, as established by the above-mentioned reference standard, data acquisition lasted for a minimum of three days, with readings every ten minutes. This time period has been increased in the case of walls with a high thickness [16]. In conclusion, it should be stressed that the measurement carried out in situ must take into account the error that was not directly calculated by the authors. For uncertainty quantification, in fact, the technical data referred to in the relative data sheets provided by the manufacturer, shown in Table 1, have been taken into consideration. 


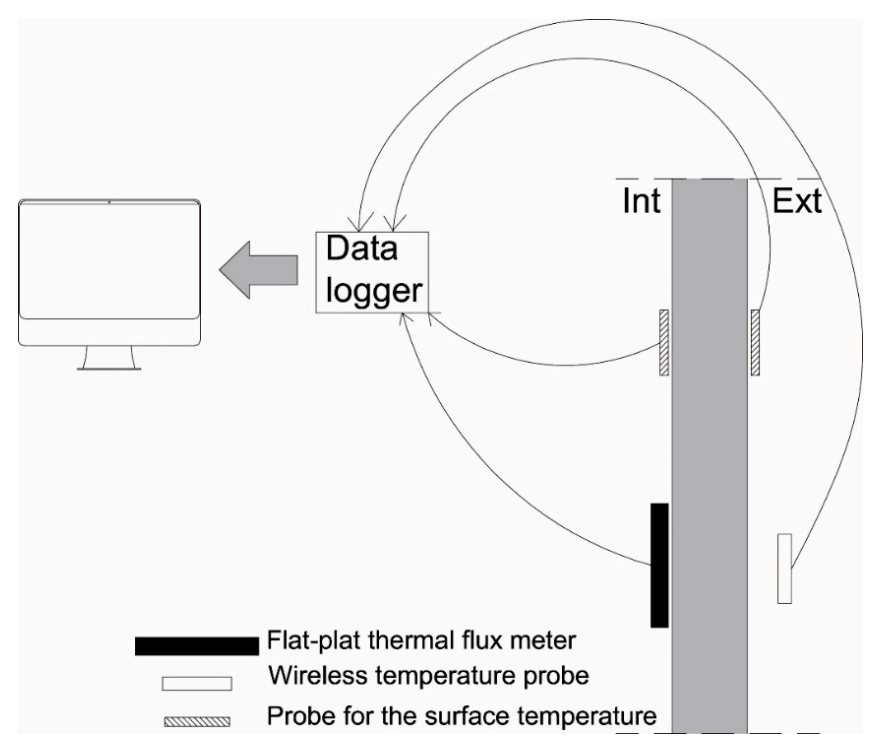

Figure 1. The graph showing the placement of the measurement devices on the wall.

Table 1. Technical data.

\begin{tabular}{|c|c|}
\hline \multicolumn{2}{|c|}{ Heat Flow Meter for Calculating U Value (ref. “Testo 0600 1635”) } \\
\hline Property & Values \\
\hline Temperature application range & -20 to $+50{ }^{\circ} \mathrm{C}$ \\
\hline Accuracy heat flow meter & $\pm 5 \%$ \\
\hline System accuracy U-value & $\pm 12 \%$ of measurement value at $15 \mathrm{~K}$ temperature difference \\
\hline \multicolumn{2}{|c|}{ Radio Probe For External Temperature (ref. "Testo 0613 1001") } \\
\hline Property & Values \\
\hline Measure range & -50 to $+275^{\circ} \mathrm{C}$ \\
\hline Accuracy & $\pm 0.5^{\circ} \mathrm{C}\left(-20.0\right.$ to $\left.+80.0{ }^{\circ} \mathrm{C}\right)$ \\
\hline & $\pm 0.8^{\circ} \mathrm{C}\left(-50.0\right.$ to $\left.-20.1^{\circ} \mathrm{C}\right)$ \\
\hline & $\pm 0.8^{\circ} \mathrm{C}\left(+80.1\right.$ to $\left.+200.0^{\circ} \mathrm{C}\right)$ \\
\hline & $\pm 1.5^{\circ} \mathrm{C}$ (remaining range) \\
\hline Resolution & $\pm 0.1^{\circ} \mathrm{C}$ \\
\hline \multicolumn{2}{|c|}{ Probe for Surface Temperature (ref. “Testo 06020644 ”) } \\
\hline Property & Values \\
\hline Measure range & -50 to $+400^{\circ} \mathrm{C}$ \\
\hline Accuracy & $\begin{array}{l}\text { Class } 2 \text { (according to standard EN } 60584-2 \text {, the accuracy of } \\
\text { Class } 2 \text { refers to }-40 \text { to }+1200^{\circ} \mathrm{C} \text { ) }\end{array}$ \\
\hline
\end{tabular}

Subsequently, all the data obtained in the measurements were extrapolated from the data logger used and reported both in graphical and tabular form. For this purpose, the software supplied directly by the manufacturer of instrumentation ("Testo Comfort" software) was used. The direct comparison between the two types of output made it possible to identify "useful" data with respect to those deriving from disturbing factors such as ignition, heating, window opening, lack of an appropriate temperature difference ... Once the abnormal "peaks" of the graphic output were identified together with their respective causes, thanks to the tables it was possible to extrapolate and isolate the corresponding measured values. This operation allowed to eliminate any disturbed values, therefore considered not reliable. It is clear that this phase is really fundamental because an incorrect analysis of the measurements results can lead to subsequent errors in the evaluation of the transmittance values. 
The last phase, the one concerning data mining and subsequent interpretation, was also developed in compliance with UNI ISO 9869, applying the "Progressive Average Method." The formula used is the following:

$$
\mathrm{U}=\frac{\sum_{j=1}^{n} q_{j}}{\sum_{j=1}^{n}\left(T_{i j}-T_{e j}\right)}
$$

where " $q$ " is the thermal flux, " $T_{i}$ " is the internal temperature, " $T_{e}$ " is the external temperature.

In general, the results obtained were considered valid when, in compliance with the "progressive average method," the value of the thermal resistance was converged asymptotically to the value sought. Finally, with the Design Builder software the model of the masonry building aggregate has been reconstructed containing the wall type under investigation and the main calculation results have been extrapolated together with the experimental analyses, in order to verify accurately the reliability of the results [23]. The term building aggregate means a set of buildings grouped together or in contact with each other, which can interact under a seismic or dynamic event in general. They generally have non-homogeneous construction characteristics and stratified over time, with more or less effective structural links between the different buildings that make it up. As mentioned, the methodology developed was verified on some types of walls in the historic village of Fontecchio, located in Italy, in the Province of L'Aquila.

\section{Results}

\subsection{Preliminary Analysis for the Selection of Wall Samples}

Before carrying out the in-situ analyses, a sampling of the wall types in the minor centre of Fontecchio was carried out. A mapping of these one has allowed to highlight the most frequent construction solutions. The presence of ten different types of wall samples emerged from this analysis.

After having classified and analysed the wall samples, all the studies necessary to choose the buildings able to guarantee the correct monitoring conditions have been carried out. This transition was rather complex as the area of interest is a small village hit by the earthquake that in 2009 strongly damaged the Province of L'Aquila and beyond. Therefore, the buildings are mostly uninhabited, characterized by internal temperatures not suitable for testing and often not characterized by confined spaces, due to collapses, partial breakages of the building envelope, ... In short, therefore, the buildings eligible for our study were very few at the end. For this reason, it was possible to analyse only four wall samples (Figure 2), which however represent a total of about $60 \%$ of the masonry present in the small village. Therefore, they can be considered a representative sample.

Following the description in detail:

- $\quad$ The wall sample no. $1-\mathrm{M} 1$, that is a masonry of partially squared, medium-sized blocks and stone flakes with plastered inner surface, of $60 \mathrm{~cm}$ thickness;

- The wall sample no. 2-M2, that is a masonry of partially squared small and medium-sized stone blocks with plastered surface, of $74 \mathrm{~cm}$ thickness;

- The wall sample no. 3-M3, that is a masonry of partially-squared, semi-sized stone blocks and stone flakes with internal and external plastered surfaces, more recent of $55 \mathrm{~cm}$ thickness;

- The wall sample no. 4-M4, that is a masonry of stones with roughly squared blocks of medium and large dimensions and flakes with internal plastered surface, of $61 \mathrm{~cm}$ thickness.

It is evident that in the case of an inhabited historical centre and in standard conditions the number of measurable samples would be higher. In the case study of Fontecchio there were many obstacles and constraints that in many cases it was necessary to repeat many tests before obtaining scientifically reliable results. 


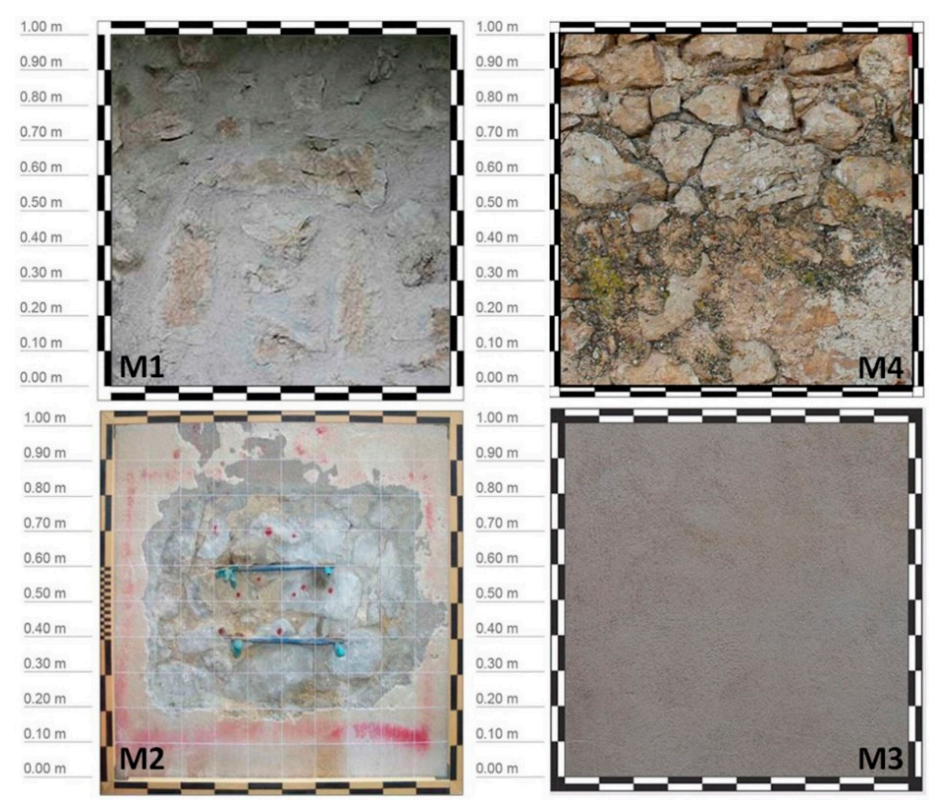

Figure 2. The four most common wall samples.

\subsection{Experimental Analyses and the Main Results}

For each of the four buildings containing the wall samples, the following activities were performed:

- metric and photographic survey of the building aggregate

- analysis of the construction technology of the masonry.

Through the data acquired visually and with non-invasive investigations, elaborated section and plant charts have been drawn up, detailing the construction elements of the building aggregate. In the subsequent phase, with the use of a thermal camera the material continuity of the perimeter walls was verified, so as to exclude the presence of foreign elements not visible to the naked eye, such as to generate thermal bridges in the actual state or in any future conditions. At this point it was possible to implement the thermal flux analysis lasting at least three days at regular intervals of $10 \mathrm{~min}$, in compliance with the UNI ISO 9869 standard. The data obtained from the measurements were filtered through the analysis described in the previous section so that the instantaneous values of transmittance measured by the thermal flux meter were processed using the progressive average method. The main results are shown below.

\subsubsection{The Wall Sample No. 1-M1}

The wall sample no. 1 chosen for monitoring, it is located in a masonry building aggregate in the south-west area of the village (Figure 3). Starting from 10 April, the measurement cycle was performed in for which the result of the transmittance calculation was equal to $2.301 \mathrm{~W} / \mathrm{m}^{2} \mathrm{~K}$. However, during the analysis of the instantaneous transmittance values recorded by the data logger of the thermal flux meter, in many cases the difference in internal-external temperature did not exceed $5-10{ }^{\circ} \mathrm{C}$. In addition, the building in which the survey was carried out was not inhabited for a long time, due to the earthquake of 2009, and the internal ideal temperature, for this reason, has been reached through the use of an electric stove. For this reason, it was decided to repeat the experimentation measurement, just to give the building the possibility of reaching stationary conditions, similar to those of an inhabited building. Once the stationary conditions were reached, experimentation was carried out again. Overall, 431 measurement cycles were performed from 12 to 15 April. The outside temperature ranged from a minimum of $4.30^{\circ} \mathrm{C}$ to a maximum of $25.50{ }^{\circ} \mathrm{C}$. The internal temperature was constant throughout the day at around $20^{\circ} \mathrm{C}$, reaching the maximum value of $21.40^{\circ} \mathrm{C}$ while 
during the night it fell to a minimum of $14.10^{\circ} \mathrm{C}$. The internal and external temperature difference reached a maximum value of $15.70{ }^{\circ} \mathrm{C}$ but there were also cases in which the two values were very close. These situations occurred during the time period between 13:00 and 15:00 of every day the measurements were taken and this led to anomalous conditions, as can easily be found in the peaks in Figure 4. At these times, the thermal flow was negative, precisely because there was an "inversion" of the same from the outside towards the inside. It was necessary to carry out the appropriate assessments and extrapolation of unreliable and not useful data, among those obtained in a tabular form, an excerpt of which is reported in Table 2. This table contains the data measured in situ, that is, the temperatures, the instantaneous transmittance, the thermal flow and the calculation of thermal gradients. On the basis of these values it was possible to calculate the values referred to in the Equation (1) shown on the right side of the same Table 2 and highlighted in grey. In this way, it was possible to obtain the transmittance values, equal to $1.740 \mathrm{~W} / \mathrm{m}^{2} \mathrm{~K}$.

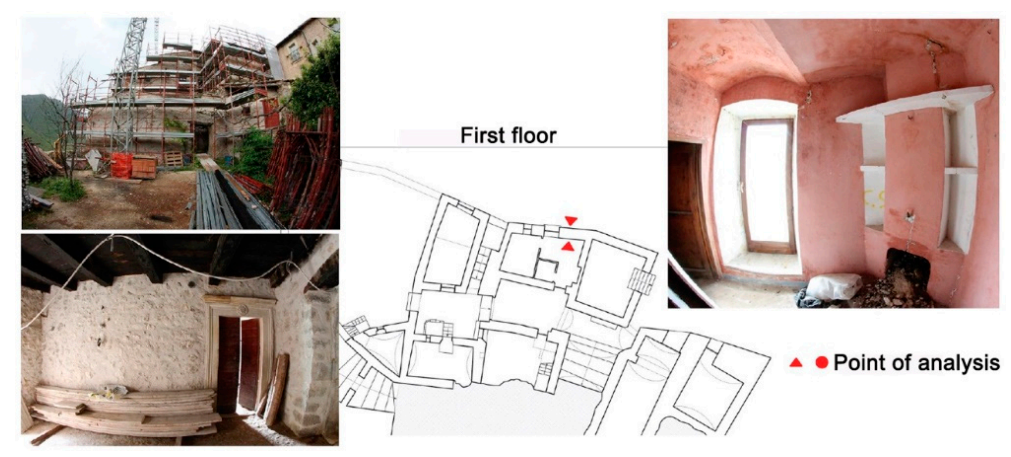

Figure 3. Point where the measurement was performed.

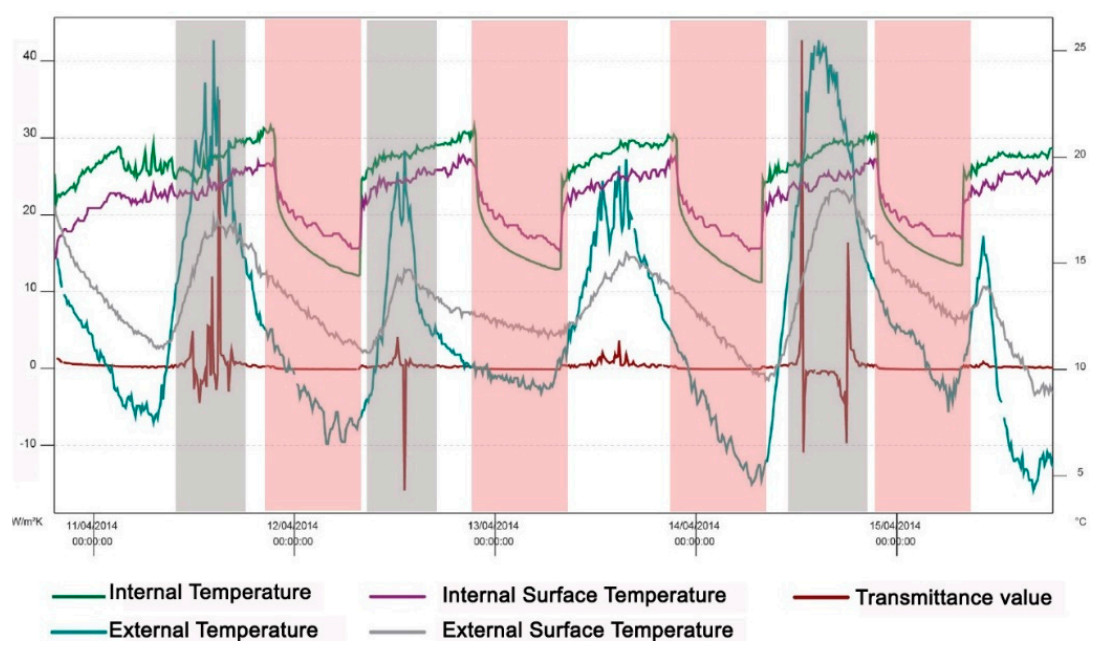

Figure 4. Part of the data detected by the thermal flux meter. Graphical output. Some anomalous peaks of the transmittance value were highlighted with the grey background. These peaks occurred because in the days of the measurements, the internal-external difference of temperature around noon, was not at least 10-15 degrees. Instead four moments at night were highlighted in pink. During these moments, the heating system was turned off because the internal temperature was close to 20 degrees and the wall collected heat because of the inertial effect. As time passed, the internal temperature decreased and the wall started to loss heat.

As previously stated, once the measurements and the survey of the building aggregate have been carried out, the model of the masonry building aggregate was reconstructed using Design Builder software, the most established and advanced user interface to EnergyPlus. Crawley, D.B. et al. and Young Tae Chae et al. told that EnergyPlus " ... is accepted worldwide to simulate annual building energy performance, HVAC systems, or thermal environment of a particular space in buildings" [34,35]. 
Table 2. On the left side, the data detected by the thermal flux meter Tabular output. In particular, in the table there are data concerning the first and the last 10 measurements, so as to highlight the variation of the parameters involved in the measurement. On the right side, against the grey background, the calculation of the variables of the Equation (1) has been inserted.

\begin{tabular}{|c|c|c|c|c|c|c|c|c|c|c|c|c|c|}
\hline N. & Day/Month/Year & Hours & $\mathrm{W} / \mathrm{m}^{2} \mathrm{~K}$ & {$\left[{ }^{\circ} \mathrm{C}\right] \mathrm{Ti}$} & {$\left[{ }^{\circ} \mathrm{C}\right] \mathrm{Te}$} & $\begin{array}{l}{\left[{ }^{\circ} \mathrm{C}\right]} \\
\text { Tse }\end{array}$ & $\begin{array}{c}{\left[{ }^{\circ} \mathrm{C}\right]} \\
\mathrm{Tsi}\end{array}$ & Ti-Te & $\underset{\left[W / m^{2}\right]}{Q}$ & Tsi-Tse & $\begin{array}{l}\text { Progressive Sum } \\
\text { of Thermal Flux }\end{array}$ & $\begin{array}{c}\text { Progressive Sum } \\
\text { Delta Ts }\end{array}$ & Conductance \\
\hline 1 & $12 / 04 / 14$ & $18: 49: 24$ & 1.378 & 20.8 & 10.8 & 12.7 & 19.5 & 10 & 13.78 & 6.8 & 13.78 & 6.8 & 2.026470588 \\
\hline 2 & $12 / 04 / 14$ & $18: 59: 24$ & 2.272 & 20.7 & 10.9 & 12.8 & 19.7 & 9.8 & 22.2656 & 6.9 & 36.0456 & 13.7 & 2.631065693 \\
\hline 3 & $12 / 04 / 14$ & 19:09:24 & 3.097 & 20.7 & 10.7 & 12.8 & 19.6 & 10 & 30.97 & 6.8 & 67.0156 & 20.5 & 3.269053659 \\
\hline 4 & $12 / 04 / 14$ & 19:19:24 & 2.817 & 20.7 & 10.7 & 12.9 & 19.5 & 10 & 28.17 & 6.6 & 95.1856 & 27.1 & 3.512383764 \\
\hline 5 & $12 / 04 / 14$ & $19: 29: 24$ & 1.671 & 20.8 & 10.7 & 12.9 & 19.5 & 10.1 & 16.8771 & 6.6 & 112.0627 & 33.7 & 3.325302671 \\
\hline 6 & $12 / 04 / 14$ & $19: 39: 24$ & 2.27 & 21 & 10.7 & 12.9 & 20 & 10.3 & 23.381 & 7.1 & 135.4437 & 40.8 & 3.319698529 \\
\hline 7 & $12 / 04 / 14$ & 19:49:24 & 2.843 & 20.8 & 10.7 & 12.8 & 19.8 & 10.1 & 28.7143 & 7 & 164.158 & 47.8 & 3.434267782 \\
\hline 8 & $12 / 04 / 14$ & $19: 59: 24$ & 2.657 & 21 & 10.4 & 12.5 & 20 & 10.6 & 28.1642 & 7.5 & 192.3222 & 55.3 & 3.477797468 \\
\hline 9 & $12 / 04 / 14$ & 20:09:24 & 2.948 & 21.2 & 10.4 & 12.7 & 20.1 & 10.8 & 31.8384 & 7.4 & 224.1606 & 62.7 & 3.575129187 \\
\hline 10 & $12 / 04 / 14$ & $20: 19: 24$ & 2.52 & 21.2 & 10.1 & 12.7 & 20 & 11.1 & 27.972 & 7.3 & 252.1326 & 70 & 3.601894286 \\
\hline$\vdots$ & $\vdots$ & : & : & $\vdots$ & : & ! & $\vdots$ & ! & ! & $\vdots$ & ! & ! & ! \\
\hline 422 & $15 / 04 / 14$ & $17: 09: 24$ & 1.996 & 20.1 & 5.8 & 9 & 19.3 & 14.3 & 28.5428 & 10.3 & 5117.0491 & 2037.5 & 2.511435141 \\
\hline 423 & $15 / 04 / 14$ & $17: 19: 24$ & 0.639 & 20.2 & 5.8 & 9.2 & 19.2 & 14.4 & 9.2016 & 10 & 5126.2507 & 2047.5 & 2.503663346 \\
\hline 424 & $15 / 04 / 14$ & $17: 29: 24$ & 0.51 & 20.2 & 6 & 9.3 & 19.1 & 14.2 & 7.242 & 9.8 & 5133.4927 & 2057.3 & 2.49525723 \\
\hline 425 & $15 / 04 / 14$ & $17: 39: 24$ & 0.688 & 20.1 & 5.5 & 8.9 & 19.1 & 14.6 & 10.0448 & 10.2 & 5143.5375 & 2067.5 & 2.48780532 \\
\hline 426 & $15 / 04 / 14$ & $17: 49: 24$ & 1.326 & 20.1 & 5.7 & 9.2 & 19.2 & 14.4 & 19.0944 & 10 & 5162.6319 & 2077.5 & 2.485021372 \\
\hline 427 & $15 / 04 / 14$ & $17: 59: 24$ & 1.788 & 20 & 6.1 & 9.1 & 19.3 & 13.9 & 24.8532 & 10.2 & 5187.4851 & 2087.7 & 2.484784739 \\
\hline 428 & $15 / 04 / 14$ & $18: 09: 24$ & 1.361 & 20.2 & 5.9 & 8.9 & 19.2 & 14.3 & 19.4623 & 10.3 & 5206.9474 & 2098 & 2.48186244 \\
\hline 429 & $15 / 04 / 14$ & $18: 19: 24$ & 0.605 & 20.4 & 6 & 9.2 & 19.3 & 14.4 & 8.712 & 10.1 & 5215.6594 & 2108.1 & 2.474104359 \\
\hline 430 & $15 / 04 / 14$ & $18: 29: 24$ & 0.768 & 20.4 & 5.6 & 9 & 19.4 & 14.8 & 11.3664 & 10.4 & 5227.0258 & 2118.5 & 2.467323956 \\
\hline 431 & $15 / 04 / 14$ & $18: 39: 24$ & 1.086 & 20.4 & 5.4 & 8.9 & 19.6 & 15 & 16.29 & 10.7 & 5243.3158 & 2129.2 & 2.462575521 \\
\hline
\end{tabular}

Ti: Internal Temperature; Te: External Temperature. Tsi: Surface temperature of the internal side of the wall. Tse: Surface temperature of the external side of the wall. 
At present, the modelling has been performed only for the building aggregate in which the M1 wall is located (Figure 5), while it is still to be developed for the other three cases.
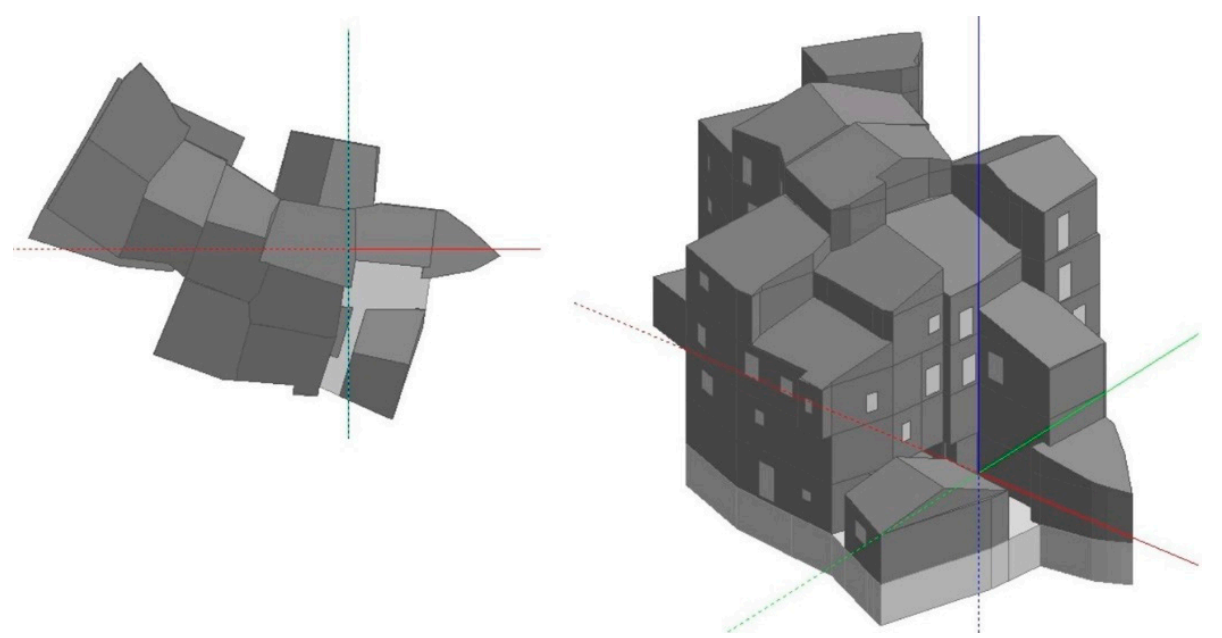

Figure 5. Use of Design Builder software to model the building containing the M1 wall sample.

\subsubsection{The Wall Sample No. 2-M2}

The wall sample no. 2 is located in a building located in the west of the village overlooking the square called "Chiassetto della Caia" (Figure 6). In this case the conditions for monitoring the behaviour of the wall were ideal because, unlike what happened with sample no. 1, the building was inhabited and therefore there was a constant internal temperature. The only inconvenience was that the wall to test was exposed to the south, so it was necessary to realize a temporary shading system. Also in this case it was necessary to repeat the test to mitigate the effects of the excessive sunshine that occurred during the first monitoring.

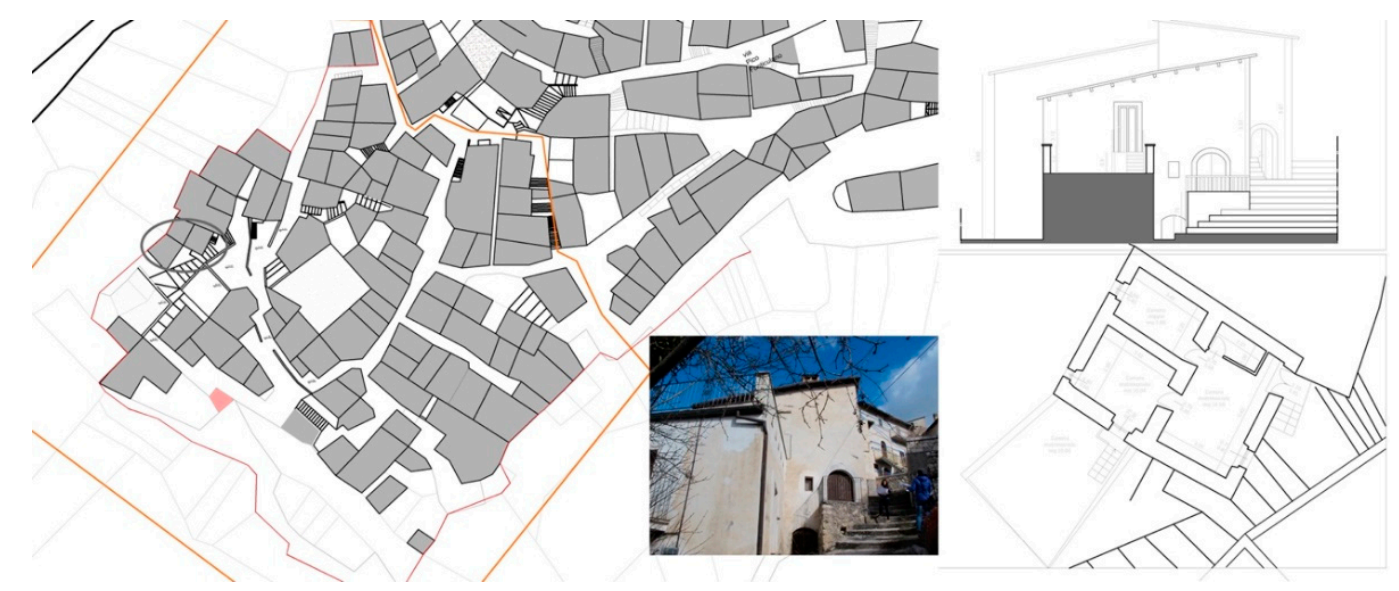

Figure 6. Point where the measurement was performed.

In relation to the M2 wall, 233 measuring cycles were performed from 21 to 23 March. The outside temperature ranged from a minimum of $3.90^{\circ} \mathrm{C}$ to a maximum of $9.70^{\circ} \mathrm{C}$. The internal temperature was constant throughout the day at around $18.00-19.00{ }^{\circ} \mathrm{C}$ reaching the maximum value of $20.50{ }^{\circ} \mathrm{C}$ and minimum equal of $18.30^{\circ} \mathrm{C}$. The internal and external temperature difference was always kept above $10.00^{\circ} \mathrm{C}$, with a maximum value of $14.50^{\circ} \mathrm{C}$, with the exception of the last four cycles during which the following values were obtained: $9.70{ }^{\circ} \mathrm{C}, 8.80^{\circ} \mathrm{C}, 8.90^{\circ} \mathrm{C}$ and $9.10^{\circ} \mathrm{C}$ (Table 3). Therefore, no anomalous situations have occurred so, except for the above mentioned last four cycles, the measured data were all considered useful. 
Table 3. On the left side, the data detected by the thermal flux meter. Tabular output. In particular, in the table there are data concerning the first and the last 10 measurements, so as to highlight the variation of the parameters involved in the measurement. The data for the last four cycles mentioned in the text can be seen. On the right side, against the grey background, the calculation of the variables of the Equation (1) has been inserted.

\begin{tabular}{|c|c|c|c|c|c|c|c|c|c|c|c|c|c|}
\hline N. & Day/Month/Year & Hours & $\mathrm{W} / \mathrm{m}^{2} \mathrm{~K}$ & {$\left[{ }^{\circ} \mathrm{C}\right] \mathrm{Ti}$} & {$\left[{ }^{\circ} \mathrm{C}\right] \mathrm{Te}$} & $\begin{array}{l}{\left[{ }^{\circ} \mathrm{C}\right]} \\
\text { Tse }\end{array}$ & $\begin{array}{c}{\left[{ }^{\circ} \mathrm{C}\right]} \\
\mathrm{Tsi}\end{array}$ & Ti-Te & $\underset{\left[W / m^{2}\right]}{Q}$ & Tsi-Tse & $\begin{array}{l}\text { Progressive Sum } \\
\text { of Thermal Flux }\end{array}$ & $\begin{array}{c}\text { Progressive Sum } \\
\text { Delta Ts }\end{array}$ & Conductance \\
\hline 1 & $21 / 03 / 15$ & 20:05:01 & 1.47 & 20.5 & 8.6 & 8.6 & 19.2 & 11.9 & 17.493 & 10.6 & 17.493 & 10.6 & 1.650283019 \\
\hline 2 & $21 / 03 / 15$ & 20:15:01 & 1.151 & 19.6 & 8.6 & 8.6 & 18.6 & 11 & 12.661 & 10 & 30.154 & 20.6 & 1.463786408 \\
\hline 3 & $21 / 03 / 15$ & 20:25:01 & 1.062 & 19.3 & 8.6 & 8.6 & 18.7 & 10.7 & 11.3634 & 10.1 & 41.5174 & 30.7 & 1.352358306 \\
\hline 4 & $21 / 03 / 15$ & 20:35:01 & 1.244 & 19.1 & 8.7 & 8.7 & 18.5 & 10.4 & 12.9376 & 9.8 & 54.455 & 40.5 & 1.344567901 \\
\hline 5 & $21 / 03 / 15$ & 20:45:01 & 1.074 & 19.1 & 8.6 & 8.6 & 18.3 & 10.5 & 11.277 & 9.7 & 65.732 & 50.2 & 1.30940239 \\
\hline 6 & $21 / 03 / 15$ & 20:55:01 & 1.207 & 19 & 8.3 & 8.3 & 18.3 & 10.7 & 12.9149 & 10 & 78.6469 & 60.2 & 1.30642691 \\
\hline 7 & $21 / 03 / 15$ & 21:05:01 & 1.029 & 18.9 & 8.3 & 8.3 & 18.2 & 10.6 & 10.9074 & 9.9 & 89.5543 & 70.1 & 1.277522111 \\
\hline 8 & $21 / 03 / 15$ & 21:15:01 & 1.213 & 18.9 & 8.3 & 8.3 & 18.3 & 10.6 & 12.8578 & 10 & 102.4121 & 80.1 & 1.278553059 \\
\hline 9 & $21 / 03 / 15$ & 21:25:01 & 1.024 & 18.9 & 8.3 & 8.3 & 18.3 & 10.6 & 10.8544 & 10 & 113.2665 & 90.1 & 1.257119867 \\
\hline 10 & $21 / 03 / 15$ & 21:35:01 & 1.182 & 18.8 & 8.1 & 8.1 & 18.5 & 10.7 & 12.6474 & 10.4 & 125.9139 & 100.5 & 1.252874627 \\
\hline$\vdots$ & $\vdots$ & : & ! & $\vdots$ & $\vdots$ & $\vdots$ & : & ! & : & : & $\vdots$ & ! & ! \\
\hline 223 & $23 / 03 / 15$ & 08:35:01 & 0.914 & 18.5 & 5.6 & 5.6 & 18 & 12.9 & 11.7906 & 12.4 & 2510.601 & 2811 & 0.893134472 \\
\hline 224 & $23 / 03 / 15$ & 08:45:01 & 1.014 & 18.4 & 5.8 & 5.8 & 18 & 12.6 & 12.7764 & 12.2 & 2523.3774 & 2823.2 & 0.893800439 \\
\hline 225 & $23 / 03 / 15$ & 08:55:01 & 0.921 & 18.5 & 5.8 & 5.8 & 17.9 & 12.7 & 11.6967 & 12.1 & 2535.0741 & 2835.3 & 0.894111417 \\
\hline 226 & $23 / 03 / 15$ & 09:05:01 & 1.092 & 18.4 & 6.4 & 6.4 & 18 & 12 & 13.104 & 11.6 & 2548.1781 & 2846.9 & 0.895071165 \\
\hline 227 & $23 / 03 / 15$ & 09:15:01 & 1.027 & 18.5 & 7.1 & 7.1 & 17.9 & 11.4 & 11.7078 & 10.8 & 2559.8859 & 2857.7 & 0.895785387 \\
\hline 228 & $23 / 03 / 15$ & 09:25:01 & 1.177 & 18.5 & 7.3 & 7.3 & 18 & 11.2 & 13.1824 & 10.7 & 2573.0683 & 2868.4 & 0.897039569 \\
\hline 229 & $23 / 03 / 15$ & 09:35:01 & 1.079 & 18.5 & 7.6 & 7.6 & 17.9 & 10.9 & 11.7611 & 10.3 & 2584.8294 & 2878.7 & 0.897915517 \\
\hline 230 & $23 / 03 / 15$ & 09:45:01 & 1.348 & 18.5 & 8.8 & 8.8 & 17.9 & 9.7 & 13.0756 & 9.1 & 2597.905 & 2887.8 & 0.899613893 \\
\hline 231 & $23 / 03 / 15$ & 09:55:01 & 1.414 & 18.5 & 9.7 & 9.7 & 17.9 & 8.8 & 12.4432 & 8.2 & 2610.3482 & 2896 & 0.901363329 \\
\hline 232 & $23 / 03 / 15$ & 10:05:01 & 1.374 & 18.5 & 9.6 & 9.6 & 17.9 & 8.9 & 12.2286 & 8.3 & 2622.5768 & 2904.3 & 0.9029979 \\
\hline 233 & $23 / 03 / 15$ & 10:15:01 & 0.557 & 18.4 & 9.3 & 9.3 & 17.8 & 9.1 & 5.0687 & 8.5 & 2627.6455 & 2912.8 & 0.902102959 \\
\hline
\end{tabular}

Ti: Internal Temperature; Te: External Temperature. Tsi: Surface temperature of the internal side of the wall. Tse: Surface temperature of the external side of the wall. 
Similar to the description of the M1 wall, Table 3 contains the data measured in situ, that is, the temperatures, the instantaneous transmittance, the thermal flow and the calculation of the thermal gradients. In function of these values it was possible to calculate the values referred to in the Equation (1) shown on the right side of the same Table 3 and highlighted in grey. In this way, it was possible to obtain the transmittance values, a result equal to $1.27 \mathrm{~W} / \mathrm{m}^{2} \mathrm{~K}$.

\subsubsection{The Wall Sample No. 3-M3}

The wall sample no. 3 is part of a masonry building aggregate consisting of a house-wall located in the east of the village of Fontecchio. Also in this case the conditions for monitoring the behaviour of the wall was not ideal because the building was not inhabited. Instead, it was possible to position the probe in a uniform, undisturbed point, equidistant from the other construction elements such as doors, windows and so forth and representative of the vertical closure as a whole. During the measurement, it was not possible to have a suitable difference of temperature, so several cycles of measurement were not taken into account. In detail, 969 measurement cycles were performed from 29 March to 5 April. The outside temperature ranged from a minimum of $2.90^{\circ} \mathrm{C}$ to a maximum of $17.30^{\circ} \mathrm{C}$. The internal temperature was rather low, in fact it never reached $20.00^{\circ} \mathrm{C}$. In particular, it has fluctuated in a range between $9.10^{\circ} \mathrm{C}$ and $14.80^{\circ} \mathrm{C}$. The internal and external temperature difference reached a maximum value of $11.00{ }^{\circ} \mathrm{C}$ but there were also cases in which the external one was higher than the internal one causing a negative value of "Ti-Te." This phenomenon occurred above all during the daytime hours while at night the gradient always returned at around $10.00{ }^{\circ} \mathrm{C}$. At these times, the thermal flow was negative, precisely because there was an "inversion" of the same from the outside towards the inside. Therefore, it was necessary to carry out the appropriate assessments and extrapolation of unreliable and not useful data, among those obtained in a tabular form, an excerpt of which is reported in Table 4. This table contains the data measured in situ, that is, the temperatures, the instantaneous transmittance, the thermal flow and the calculation of thermal gradients. On the basis of these values it was possible to calculate the values referred to in the Equation (1) shown on the right side of the same Table 4 and highlighted in grey. In this way, it was possible to obtain the transmittance values, equal to $1.98 \mathrm{~W} / \mathrm{m}^{2} \mathrm{~K}$ (Figures 7 and 8 ).
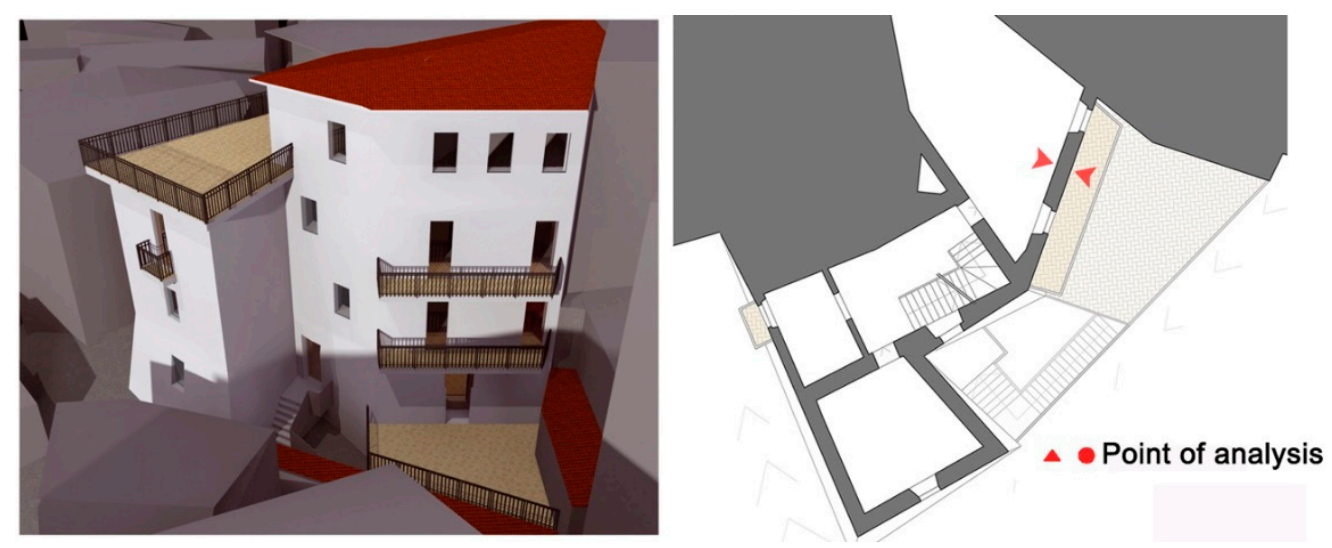

Figure 7. Point where the measurement was performed. 
Table 4. On the left side, the data detected by the thermal flux meter. Tabular output. In particular, the data in the table concern the first and the last 10 measurements, so as to highlight the variation of the parameters involved in the measurement. As mentioned, during the day, it was not possible to have a suitable difference of temperature, so the measurements were not taken into account. On the right side, against the grey background, the calculation of the variables referred to in the Equation (1) was inserted.

\begin{tabular}{|c|c|c|c|c|c|c|c|c|c|c|c|c|c|}
\hline N. & Day/Month/Year & Hours & $\mathrm{W} / \mathrm{m}^{2} \mathrm{~K}$ & {$\left[{ }^{\circ} \mathrm{C}\right] \mathrm{Ti}$} & {$\left[{ }^{\circ} \mathrm{C}\right] \mathrm{Te}$} & $\begin{array}{l}{\left[{ }^{\circ} \mathrm{C}\right]} \\
\text { Tse }\end{array}$ & $\begin{array}{c}{\left[{ }^{\circ} \mathrm{C}\right]} \\
\text { Tsi }\end{array}$ & Ti-Te & $\underset{\left[\mathrm{W} / \mathrm{m}^{2}\right]}{\mathrm{Q}}$ & Tsi-Tse & $\begin{array}{l}\text { Progressive Sum } \\
\text { of Thermal Flux }\end{array}$ & $\begin{array}{c}\text { Progressive Sum } \\
\text { Delta Ts }\end{array}$ & Conductance \\
\hline 1 & $29 / 03 / 13$ & 17:03:00 & -3.593 & 12.6 & 15.4 & 14 & 9 & -2.8 & -10.0604 & -5 & -10.0604 & -5 & 2.01208 \\
\hline 2 & $29 / 03 / 13$ & 17:13:00 & -0.335 & 10.1 & 15.1 & 14 & 8.9 & -5 & -1.675 & -5.1 & -11.7354 & -10.1 & 1.161920792 \\
\hline 3 & $29 / 03 / 13$ & $17: 23: 00$ & -0.308 & 9.5 & 15.2 & 13.8 & 8.7 & -5.7 & -1.7556 & -5.1 & -13.491 & -15.2 & 0.887565789 \\
\hline 4 & $29 / 03 / 13$ & $17: 33: 00$ & -0.474 & 9.3 & 14.5 & 13.5 & 8.9 & -5.2 & -2.4648 & -4.6 & -15.9558 & -19.8 & 0.805848485 \\
\hline 5 & $29 / 03 / 13$ & 17:43:00 & -0.548 & 9.2 & 14.5 & 13.6 & 9 & -5.3 & -2.9044 & -4.6 & -18.8602 & -24.4 & 0.772959016 \\
\hline 6 & $29 / 03 / 13$ & 17:53:00 & -0.602 & 9.1 & 14.3 & 13.3 & 9 & -5.2 & -3.1304 & -4.3 & -21.9906 & -28.7 & 0.766222997 \\
\hline 7 & $29 / 03 / 13$ & 18:03:00 & -0.681 & 9.1 & 14.1 & 13.5 & 9.2 & -5 & -3.405 & -4.3 & -25.3956 & -33 & 0.769563636 \\
\hline 8 & $29 / 03 / 13$ & 18:13:00 & -0.743 & 9.1 & 13.9 & 13.2 & 9.3 & -4.8 & -3.5664 & -3.9 & -28.962 & -36.9 & 0.784878049 \\
\hline 9 & $29 / 03 / 13$ & $18: 23: 00$ & -0.937 & 9.1 & 13.4 & 13.2 & 9.3 & -4.3 & -4.0291 & -3.9 & -32.9911 & -40.8 & 0.808605392 \\
\hline 10 & $29 / 03 / 13$ & 18:33:00 & -1.005 & 9.1 & 13.1 & 13 & 9.4 & -4 & -4.02 & -3.6 & -37.0111 & -44.4 & 0.833583333 \\
\hline$\vdots$ & ! & $\vdots$ & ! & $\vdots$ & : & $\vdots$ & $\vdots$ & $\vdots$ & ! & : & ! & ! & ! \\
\hline 959 & $05 / 04 / 13$ & 08:43:00 & 2.931 & 13.3 & 10.2 & 9.4 & 13.5 & 3.1 & 9.0861 & 4.1 & 7148.6033 & 4560.9 & 1.567366814 \\
\hline 960 & $05 / 04 / 13$ & 08:53:00 & 3.264 & 13.4 & 10.3 & 9.7 & 13.5 & 3.1 & 10.1184 & 3.8 & 7158.7217 & 4564.7 & 1.568278682 \\
\hline 961 & $05 / 04 / 13$ & 09:03:00 & 3.837 & 13.5 & 10.7 & 9.8 & 13.4 & 2.8 & 10.7436 & 3.6 & 7169.4653 & 4568.3 & 1.569394589 \\
\hline 962 & $05 / 04 / 13$ & 09:13:00 & 4.375 & 13.6 & 11 & 10.1 & 13.6 & 2.6 & 11.375 & 3.5 & 7180.8403 & 4571.8 & 1.570681198 \\
\hline 963 & $05 / 04 / 13$ & 09:23:00 & 4.863 & 13.6 & 11.1 & 10.2 & 13.7 & 2.5 & 12.1575 & 3.5 & 7192.9978 & 4575.3 & 1.572136865 \\
\hline 964 & $05 / 04 / 13$ & 09:33:00 & 6.052 & 13.7 & 11.6 & 10.5 & 13.8 & 2.1 & 12.7092 & 3.3 & 7205.707 & 4578.6 & 1.57377954 \\
\hline 965 & $05 / 04 / 13$ & 09:43:00 & 6.099 & 13.7 & 11.7 & 10.6 & 13.8 & 2 & 12.198 & 3.2 & 7217.905 & 4581.8 & 1.57534266 \\
\hline 966 & $05 / 04 / 13$ & 09:53:00 & 6.621 & 13.8 & 11.9 & 10.7 & 13.9 & 1.9 & 12.5799 & 3.2 & 7230.4849 & 4585 & 1.576986892 \\
\hline 967 & $05 / 04 / 13$ & 10:03:00 & 6.617 & 13.8 & 11.8 & 10.8 & 13.8 & 2 & 13234 & 3 & 7243.7189 & 4588 & 1.578840214 \\
\hline 968 & $05 / 04 / 13$ & 10:13:00 & 10.097 & 13.9 & 12.6 & 11.1 & 13.9 & 1.3 & 13.1261 & 2.8 & 7256.845 & 4590.8 & 1.580736473 \\
\hline 969 & $05 / 04 / 13$ & 10:23:00 & 10.159 & 14.1 & 12.3 & 11.1 & 14 & 1.8 & 18.2862 & 2.9 & 7275.1312 & 4593.7 & 1.583719268 \\
\hline
\end{tabular}

Ti: Internal Temperature; Te: External Temperature. Tsi: Surface temperature of the internal side of the wall. Tse: Surface temperature of the external side of the wall. 


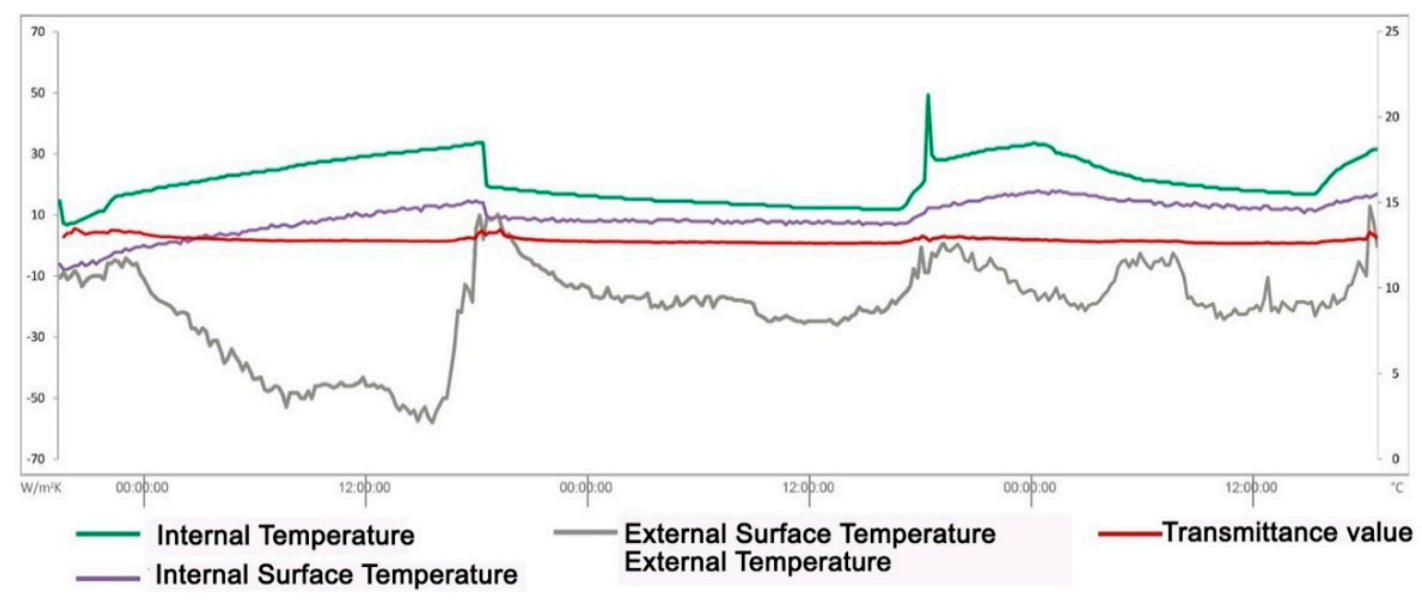

Figure 8. Part of the data detected by the thermal flux meter. Graphical output.

\subsubsection{The Wall Sample No. 4-M4}

Also, the wall sample no. 4 is located in a house-wall and, in this case, it was not necessary to repeat the tests since the monitoring conditions were ideal.

In relation to the M4 wall, 250 measurement cycles were performed from 11 to 13 April. The outdoor temperature was variable between a minimum of $3.10^{\circ} \mathrm{C}$ and a maximum of $8.00^{\circ} \mathrm{C}$. The internal temperature was constant throughout the day around $17.00-18.00^{\circ} \mathrm{C}$ reaching the maximum value equal to $18.80{ }^{\circ} \mathrm{C}$ and minimum equal to $16.90{ }^{\circ} \mathrm{C}$. The internal and external temperature difference was always kept above $10.00^{\circ} \mathrm{C}$, with a maximum value of $15.30^{\circ} \mathrm{C}$, with the exception of the first cycles in which the minimum value equal to $9.10^{\circ} \mathrm{C}$ was reached. Therefore, no anomalous situations have occurred so, with the exception of the above mentioned first cycles, the measured data have all been considered useful.

Applying the progressive average method to the instantaneous transmittance values recorded by the Data Logger of the thermal flux meter the experimental result obtained was equal to $1.815 \mathrm{~W} / \mathrm{m}^{2} \mathrm{~K}$ (Figure 9) referred to a trial period starting from 10 April.

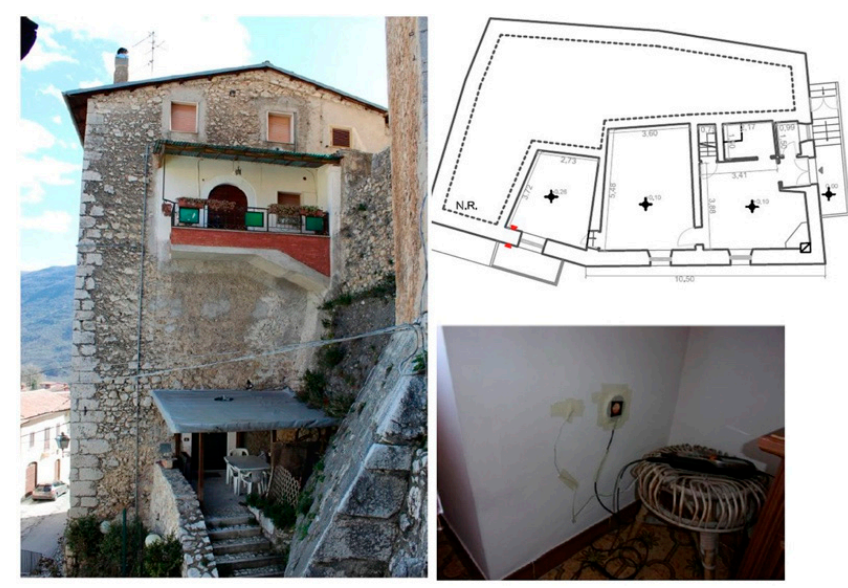

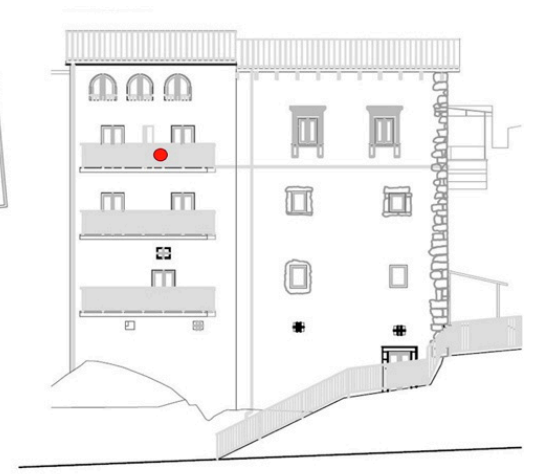

$\Delta$ Point of analysis

Figure 9. Point where the measurement was performed.

\section{Discussion}

The values measured on the four samples analysed do not reflect the literature data. In fact, according to the study "Building Typology Brochure-Italy" made by the research group Tebe of the Politecnico di Torino [10], among the main Italian building typologies, identified with the support of literature and technical regulations, it is possible to detect the masonry in stone plastered with transmittance values oscillating between 2.00 and $2.40 \mathrm{~W} / \mathrm{m}^{2} \mathrm{~K}$ depending on the wall thickness. 
The UNI TS 11300 Part 1 defines with greater precision the thermal transmittance of masonry in plastered stone according to the thickness: from $30 \mathrm{~cm}$ up to a maximum of $60 \mathrm{~cm}$. This transmittance decreases from a maximum of $2.99 \mathrm{~W} / \mathrm{m}^{2} \mathrm{~K}$ for the thinner wall up to a minimum of $2.00 \mathrm{~W} / \mathrm{m}^{2} \mathrm{~K}$ for the thicker one. The values measured in the historical centre of Fontecchio vary between 1.27 and $1.98 \mathrm{~W} / \mathrm{m}^{2} \mathrm{~K}$, as summarized in Table 5 .

Table 5. Data summary. For each of the four types of masonry the measurement values were reported and compared with the values defined by the current regulations.

\begin{tabular}{cccc}
\hline Type of Masonries & $\begin{array}{c}\text { Thickness } \\
(\mathbf{c m})\end{array}$ & $\begin{array}{c}\text { U-Values }\left(\mathbf{W} / \mathbf{m}^{2} \mathbf{K}\right) \\
\text { (UNI-TS 11300) }\end{array}$ & $\begin{array}{c}\text { U-Values (W/m } \mathbf{2}^{\mathbf{~ K})} \\
\text { (UNI ISO 9869) }\end{array}$ \\
\hline M1 & 60 & 2.00 & 1.74 \\
M2 & 74 & - & 1.27 \\
M3 & 55 & 2.11 & 1.98 \\
M4 & 61 & - & 1.81 \\
\hline
\end{tabular}

As shown in the table, a significant difference was found between the measured and the regulatory values, in particular the former are lower than those recorded in the literature. Specifically, the variation recorded is equal to about $10-15 \%$ for the types of walls M1 and M3. On the other hand, it is not possible to make comparisons for walls of type M2 and M4 because, having a thickness of more than $60 \mathrm{~cm}$, there are no transmittance values recorded in the reference standard. In the absence of measurements and of real data concerning the transmittance of the walls of the building envelope, it is clear that the rehabilitation project will not respect the real needs of the building. The importance of an in-depth knowledge of the real behaviour of an existing historical envelope of a building is therefore fundamental, given that any evaluation mistake can have serious consequences from both an economic and environmental point of view. Underestimating the transmittance of a wall involves the use of a greater amount of insulating material or, in any case, of more performing material to comply with current legislation; therefore, it implies a waste in the use of available resources but also the disposal of greater quantities of building materials in relation to the end of life.

The results obtained on the analysed wall samples can be considered significant because they are recurrent in the particular context under investigation. But they are also relevant for other historic centres located in the already mentioned "Limestone area of L'Aquila" [28] whose buildings were built with the same type of stone laid in masonry that in most cases remained intact and not subject to rework over the years. The importance of the results obtained is evident in relation to the recurrence of the historical construction techniques, of the stones used from the same limestone quarries, ... They are therefore easily exportable even in many villages scattered with the Province of L'Aquila. For this reason, they allow a step forward in scientific knowledge in relation to minor historical buildings. Furthermore, the results presented here are of considerable value if we take into consideration the fact that this territory is currently the subject of an important post-earthquake reconstruction activity which involves the use of public funds also for the energy redevelopment of the building envelopes. It is evident the importance for designers to have real data for comparison to ensure greater rationality in the use of resources, both environmental and economic. Also in light of the fact that very often we need to turn to experts to perform measurements in situ to get such data. To make this situation more difficult, there is also the impossibility to make measurements as often the buildings under study do not have confined spaces any more (due to collapses, broken windows, ... ), so it is not possible to heat the rooms. Therefore, the results obtained are considered to be meaningful only for the "insiders" working in the particular context investigated.

But the study previously illustrated and the methodology explained are very relevant also at a general level because the study of the state of the art revealed the lack of strategies and methods to implement a rehabilitation intervention on historical buildings, with the exception of the few pilot experiences mentioned. And this despite the fact that this topic is relevant at an international level. 


\section{Conclusions}

Knowledge of the energetic behaviour of historic buildings is a highly topical subject at the international level but despite this, no effective methods and instruments recognized at European level have been identified. Furthermore, in the specific context of Italy, Legislative Decree 192.2005 and s.m.i. has imposed the respect of certain transmittance values, defined as "limit," in the intervention on historical building envelopes. This imposition does not take into account the construction techniques, the local peculiarities, the construction period of the building structure ... and above all the difficulty of identifying design solutions that are effective and compatible due to the lack of specific data on the thermal characteristics of masonry walls. Therefore, it is evident the need to deepen this line of research through the development of methodologies and best practices in order to produce systemic actions. This paper follows this line of research and has illustrated a methodology where the thermal performance of historical masonries has been measured using the heat flow-meter measurement (HFM), a Non Destructive Testing (NDT) that permits determination of the thermal transmittance properties of the opaque envelope directly in situ. The procedure is regulated by the standard UNI ISO 9869: 1994.

The methodology proposed involves the development of some phases aimed at identifying the most recurring sample wall panels. In the specific village under study, it was possible to identify four wall samples. This is because, being a historic centre hit by the earthquake of 2009, it was not possible to verify the context conditions of many buildings without which the measurement cannot be considered valid. The results obtained show a significant difference between the measured and the normative values, in particular the former are lower than those of the literature. Specifically, the variation recorded is equal to about $10-15 \%$ for the types of walls M1 and M3. For the other two there are no reference values of literature. The work presented in this paper is only a first part of a broader research aimed at increasing knowledge on the properties of historical walls. As the village di Fontecchio returns to be inhabited and its buildings accessible and confined, this research will be continued by analysing further samples in order to draw up a reference database. Then the research will be extended to the other neighbouring centres this database can be made available to researchers but also professionals and representatives of the authorities in order to be able to intervene with awareness on the types of masonry analysed.

The developed measurement results and methodology can be easily replicated in other contexts and extended to all the building elements that make up the historical envelope.

A further scenario of future development that the authors are interested in is the assessment of the negative effects that derive from a wrong evaluation of the thermal transmittance of the walls of historic buildings, especially in relation to the disposal of building materials. In fact according to all recent directive of European Union [36], it is necessary to define alternative strategies to the disposal of high quantities of building materials. Analysing the scientific literature, it is possible to find interesting technological solutions and related environmental benefits coming from wall recycling [37]. However, there is a clear fragmentation in economic aspects related to this scope. For this reason the future step is to develop a financial model finalized to assess the profitability of recycling in this sector. The model will be based on the main economic indexes, represented by the Net Present Value (NPV) and the Discounted Payback Period (DPBT).

Author Contributions: M.R. conceived and designed the experiments and the methodology; she defined the structure, organization and editing of the article; F.C. was responsible for a part of scientific research; P.D.B. was responsible for the scientific research. V.S.'s contribution is limited to the preliminary analysis of the sensory system for long and short-term building analysis and electronic equipment performance and for the developed measurement setup. M.R., F.C. and V.S. wrote Sections 1 and 5. M.R. also wrote Sections 2-4.

Funding: This research received no external funding.

Conflicts of Interest: The authors declare no personal conflict of interest. 


\section{References}

1. Oh, J.; Yoo, H.; Kim, S. Evaluation of Strategies to Improve the Thermal Performance of Steel Frames in Curtain Wall Systems. Energies 2016, 9, 1055. [CrossRef]

2. Allen, A.D. The Role of History in Place Marketing: Can Branding Create a Sense of Place? J. Town City Manag. 2011, 2, 75-83.

3. Rotilio, P.E.M.; De Berardinis, P.E.P.; Marchionni, C. Principles of sustainability in the Reconstruction Plans of the minor centres struck by the earthquake. A case study: Sant'Eusanio Forconese (Aq). CINECA IRIS Inst. Res. Inf. Syst. 2013. [CrossRef]

4. Kim, S.-H.; Lee, J.-H.; Kim, J.-H.; Yoo, S.-H.; Jeong, H.-G. The Feasibility of Improving the Accuracy of In Situ Measurements in the Air-Surface Temperature Ratio Method. Energies 2018, 11, 1885. [CrossRef]

5. Evangelisti, L.; Battista, G.; Guattari, C.; Basilicata, C.; de Lieto Vollaro, R. Influence of the Thermal Inertia in the European Simplified Procedures for the Assessment of Buildings' Energy Performance. Sustainability 2014, 6, 4514-4524. [CrossRef]

6. Foucquier, A.; Robert, S.; Suard, F.; Stéphan, L.; Jay, A. State of the art in building modelling and energy performances prediction: A review. Renew. Sustain. Energy Rev. 2013, 23, 272-288. [CrossRef]

7. Evangelisti, L.; Guattari, C.; Gori, P.; Vollaro, R. In Situ Thermal Transmittance Measurements for Investigating Differences between Wall Models and Actual Building Performance. Sustainability 2015, 7, 10388-10398. [CrossRef]

8. Laurenti, L.; Marcotullio, F. La Valutazione Della Trasmittanza Termica; Cda (Condizionamento dell'aria, riscaldamento, refrigerazione): Milano, Italy, 2009.

9. Cucchiella, F.; D’Adamo, I.; Gastaldi, M. Economic Analysis of a Photovoltaic System: A Resource for Residential Households. Energies 2017, 10, 814. [CrossRef]

10. Corrado, V.; Ballarini, I.; Corgnati, S.P.; Talà, N. Building Typology Brochure-Italy; Politecnico di Torino: Torino, Italy, 2011; pp. 3-20.

11. UNI 10351:1994. Building Materials. Thermal Conductivities and Vapor Permeabilities; UNI-Italian Organization for Standardization: Milano, Italy, 2018.

12. UNI 10355. Walls and Floors_-Values of Thermal Resistance and Calculation Methods; UNI-Italian Organization for Standardization: Milano, Italy, 2014.

13. UNI/TS 11300-1. Part 1: Evaluation of Energy Need for Space Heating and Cooling; UNI-Italian Organization for Standardization: Milano, Italy, 2014.

14. ISO 9869:1994. Thermal Insulation-Building Elements-In-Situ Measurement of Thermal Resistance and Thermal Transmittance; ISO: Geneva, Switzerland, 1994.

15. Choi, D.S.; Ko, M.J. Comparison of Various Analysis Methods Based on Heat Flowmeters and Infrared Thermography Measurements for the Evaluation of the In Situ Thermal Transmittance of Opaque Exterior Walls. Energies 2017, 10, 1019. [CrossRef]

16. Adhikari, R.S.; Lucchi, E.; Pracchi, V. Experimental Measurements on Thermal Transmittance of the Opaque Vertical Walls in the Historical Buildings. In Proceedings of the 28th International Plea Conference, Lima, Peru, 7-9 November 2012.

17. Bellia, L.; d'Ambrosio Alfano, F.R.; Giordano, J.; Ianniello, E.; Riccio, G. Energy requalification of a historical building: A case study. Energy Build. 2015, 95, 184-189. [CrossRef]

18. Rospi, G.; Cardinale, N.; Negro, E. Energy Performance and Economic Feasibility Study of Historical Building in the City of Matera, Southern Italy. Energies 2017, 10, 2009. [CrossRef]

19. Pantoli, L.; Muttillo, M.; Ferri, G.; Stornelli, V.; Alaggio, R.; Vettori, D.; Chinzari, L.; Chinzari, F. Remote Sensing System for Condition Monitoring of Modern Wooden Structures. In Proceedings of the 49th Annual Meeting of the Associazione Società Italiana di Elettronica, Palermo, Italy, 21-23 June 2017.

20. Pantoli, L.; Muttillo, M.; Ferri, G.; Stornelli, V.; Alaggio, R.; Chinzari, F. Distributed sensing and monitoring system for wooden structures. In Proceedings of the SAC Sensors and Actuators Congress, Stockholm, Sweden, 3-6 September 2018.

21. de Rubeis, T.; Muttillo, M.; Pantoli, L.; Nardi, I.; Leone, I.; Stornelli, V.; Ambrosini, D. A first approach to universal daylight and occupancy control system for any lamps: Simulated case in an academic classroom. Energy Build. 2017, 152, 24-39. [CrossRef] 
22. Tanasiev, V.; Necula, H.; Darie, G.; Badea, A. Web service-based monitoring system for smart management of the buildings. In Proceedings of the International Conference and Exposition on Electrical and Power Engineering (EPE), Iasi, Romania, 16-18 October 2014; pp. 23-25.

23. De Berardinis, P.; Rotilio, M.; Marchionni, C.; Friedman, A. Improving the energy-efficiency of historic masonry buildings. A case study: A minor centre in the Abruzzo region, Italy. Energy Build. 2014, 80, 415-423. [CrossRef]

24. Kim, S.-H.; Kim, J.-H.; Jeong, H.-G.; Song, K.-D. Reliability Field Test of the Air-Surface Temperature Ratio Method for In Situ Measurement of U-Values. Energies 2018, 11, 803. [CrossRef]

25. Lucchi, E. Thermal transmittance of historical brick masonries: A comparison among standard data, analytical calculation procedures, and in situ heat flow meter measurements. Energy Build. 2017, 134, 171-184. [CrossRef]

26. Lucchi, E. Thermal transmittance of historical stone masonries: A comparison among standard, calculated and measured data. Energy Build. 2017, 151, 393-405. [CrossRef]

27. Baker, P. U-Values and Traditional Buildings: In Situ Measurements and Their Comparisons to Calculated Values; Hostoric Scotland: Edinburgh, UK, 2011.

28. Morganti, R.; De Berardinis, P.; Bellicoso, A.; Di Giovanni, G.; Tosone, A.; Marcotullio, F. Energy rehabilitation in the post seismic reconstruction. In Proceedings of the 39th IAHS Changing needs, Adaptive Buildings Smart Cities, Milan, Italy, 17-20 September 2013; pp. 877-885.

29. Brusaporci, S. Le murature Nell'architettura del Versante Meridionale del Gran Sasso (secc. XI-XIV); Gangemi Editore: Roma, Italy, 2007.

30. Bonamico, S.; Tamburini, G. Centri Storici Minori; Politecnico di Torino: Turin, Italy, 1995.

31. Zordan, L.; Bellicoso, A.; De Berardinis, P.; Di Giovanni, G.; Morganti, R. Le Tradizioni del Costruire della Casa in Pietra: Materiali, Tecniche, Modelli e Sperimentazioni; Amazon: Seattle, WA, USA, 2002; Volume 1.

32. Genova, E.; Fatta, G. The thermophysical characterization of technical elements in the historic architecture: Experiences in Palermo. In Proceedings of the Actas del Congreso Internacional de Eficiencia Energética y Edificación Histórica, Madrid, Spain, 29-30 September 2014; pp. 397-406.

33. Albatici, R.; Tonelli, A. Verifica Sperimentale In Situ, con Analisi Termografiche e Algoritmi di Calcolo, della Trasmittanza Termica di un Elemento Costruttivo; Museo Civico di Rovereto: Rovereto, Italy, 2008; pp. 103-125.

34. Crawley, D.B.; Hand, J.W.; Kummert, M.; Griffith, B.T. Contrasting the capabilities of building energy performance simulation programs. Build. Environ. 2008, 43, 661-673. [CrossRef]

35. Chae, Y.; Lee, Y.; Longinott, D. Assessment of Retrofitting Measures for a Large Historic Research Facility Using a Building Energy Simulation Model. Energies 2016, 9, 466. [CrossRef]

36. European Commission. EU Construction \& Demolition Waste Management Protocol; European Commission: Brussels, Belgium, 2018.

37. Sivrikaya, O.; Kıyıldı, K.R.; Karaca, Z. Recycling waste from natural stone processing plants to stabilise clayey soil. Environ. Earth Sci. 2013, 71, 4397-4407. [CrossRef] 